\title{
The Effect of an Educational Program Based on the Health Belief Model on Self-Efficacy among Patients with Type 2 Diabetes Referred to the Iranian Diabetes Association
} in 2014

\author{
Sheida Vahidi' ${ }^{1}$, Sima Esmaeili Shahmirzadi², Davoud Shojaeizadeh ${ }^{2}$, Hamid Haghani \\ Soghra Nikpour ${ }^{*}$ \\ ${ }^{1}$ Treatment Affairs, Shahid Beheshti University of Medical Sciences, Tehran, Iran \\ ${ }^{2}$ Department of Health Education \& Promotion, School of Public Health, Tehran University of Medical Sciences, \\ Tehran, Iran \\ ${ }^{3}$ Department of Biostatistics, School of Management and Information, Iran University of Medical Sciences, \\ Tehran, Iran \\ ${ }^{4}$ Center for Nursing Care Research, School of Nursing and Midwifery, Iran University of Medical Sciences, \\ Tehran, Iran \\ Email: $\underline{\text { s nikpour@iums.ac.ir }}$
}

Received 9 July 2015; accepted 3 August 2015; published 6 August 2015

Copyright (C) 2015 by authors and Scientific Research Publishing Inc.

This work is licensed under the Creative Commons Attribution International License (CC BY). http://creativecommons.org/licenses/by/4.0/

(c) (i) Open Access

\section{Abstract}

Background: Patient self-efficacy is one of the most important factors in treating and overcoming disease. Objective: The aim of this study was to evaluate the effect of an educational program based on the health belief model on self-efficacy among patients with type 2 diabetes referred to the Iranian Diabetes Association in 2014. Method: A randomized controlled clinical trial was conducted. Eighty patients with type 2 diabetes were selected randomly by the double block sample method. They were then divided into two groups of intervention and control (40 patients in each group) by random allocation. Data were collected by a questionnaire based on the Health Belief Model and self-efficacy. The data were gathered two months after the educational program was held. The educational program was designed on the basis of data collected in the pre-test phase. Then, the educational program was executed for the intervention group in 8 sessions (each 30 minutes) using lectures and an educational booklet. Data analysis was done with Chi-square Test, Pearson's correlation, Independent samples T-test and paired T-test. The significance level was

\footnotetext{
${ }^{*}$ Corresponding author.

How to cite this paper: Vahidi, S., Shahmirzadi, S.E., Shojaeizadeh, D., Haghani, H. and Nikpour, S. (2015) The Effect of an Educational Program Based on the Health Belief Model on Self-Efficacy among Patients with Type 2 Diabetes Referred to the Iranian Diabetes Association in 2014. Journal of Diabetes Mellitus, 5, 181-189.
} 
considered at 0.05. Results: Before intervention, no significant difference was detected between the two groups. However, after intervention all variables were significantly different except for perceived threat. Moreover, there were significant linear relationships between Self-efficacy and all Health Belief Model components after the educational intervention in both groups $(p<0.05)$. Conclusion: The educational program based on the health belief model increased self-efficacy in type 2 diabetes mellitus patients.

\section{Keywords}

\section{Self-Efficacy, Health Belief Model, Type 2 Diabetes}

\section{Introduction}

Nowadays, diabetes has become the world's largest epidemic [1]. Diabetes mellitus is a common chronic disorder in the western world. In 2007, an estimated 246 million adults aged 20 - 79 years were diagnosed with diabetes, compared to 194 million in 2003 [2]. Recent data from the National Survey of Risk Factors for NonCommunicable Diseases in Iran reported that $7.7 \%$ of Iranian adults had diabetes, half of which had remained undiagnosed, and that another $16.8 \%$ of the Iranian population had impaired fasting glucose. The increasing prevalence of diabetes among employed adults is an ominous sign for a developing nation; predictions are that diabetes will be the leading cause of disease burden among Iranians in the future [3]. The health belief model (HBM) is one of the most widely used models in the public health theoretical framework. It is a useful and applicable framework for developing and implementing programs to encourage healthy behaviors [4] [5]. Patient self-efficacy is a key element in the prevention and treatment of disease [4] [6]. Patients' self-care behaviors are determined by their health beliefs [7]. Although professionals have tried to explain the value of self-care behaviors to patients, they are often not achieved by them [8]. On the other hand, studies have shown that patient self-efficacy and health beliefs are highly correlated with each other.

According to previous studies, all the components of the HBM change significantly after educational interventions, confirming that HBM constructs cause changes that improve patient behavior in taking care of themselves [9] [10]. So the effects of self-efficacy on all HBM components and educational programs are necessary for improving diabetic self-care [6]. The heath belief model is a theoretical and conceptual framework that can be used in a variety of situations. It has served as a successful model in a number of health education programs [11]. Thus, the main purpose of this study was to find the effect of an educational program based on the HBMon self-efficacy among type 2 diabetic patients referred to the Iranian Diabetes Association (IDA) in 2014.

\section{Subjects and Methods}

\subsection{Study Design and Participants}

This study was a non-blinded randomized controlled clinical trial. The study population consisted of all patients with type 2 diabetes referred to the Iranian Diabetes Association in 2014 to control their condition. Inclusion criteria included; age: 30 - 70 years, having a medical record in the IDA, having not received a formal education about diabetes, literate individuals, having had no learning disorders, having had a landline phone. Exclusion criteria included: having a severe mental disorder, having had a history of chronic or severe vision \& hearing problems. Informed consent was obtained from all participants. Participants in both the intervention and control groups were homogenous in terms of their demographic characteristics.

The sample size was 80 , determined by the following sample size formula for comparing the mean in two groups (test power of $95 \%$ and probability error of 0.05 ) [12] [13]:

$$
N=\frac{1}{1-f}\left(\frac{2\left(\mathrm{Z}_{\alpha}+\mathrm{Z}_{\beta}\right)^{2} S^{2}}{\left(\mu_{1}-\mu_{2}\right)^{2}}\right.
$$

In this randomized controlled trial, 80 patients with diabetes were randomly allocated into Intervention Group 
or Control Group. Educational classes booklets. In the intervention group were used during one day a week for 30 minutes during the 2-month. The control group has not received the interventional program.

The patients were randomly allocated to two groups of intervention and control groups using 40 red and 40 white cards as follows: For every two individuals, the one with the red card would be assigned to the intervention group, and the immediate next person would be assigned to the control group. The process continued until all the patients were assigned to the two groups. The participants' response rate was $100 \%$, and there was no sample loss. Data was collected by two means; patients' medical records and a questionnaire completed upon interview. Interviews were conducted with the patients before and six months after the training.

\subsection{Data Collection Tool}

The questionnaire included demographic characteristics, HBM components including; knowledge, perceived susceptibility-threats-benefits \& barrier, cues to action, and data regarding patient self-efficacy. The questionnaire was designed by Health Education academic teachers [14]-[16]. Among demographic variable" Economic situation" was measured by self-report method" how do you assess your economic situation?

Qualitative and quantitative methods were used to determine the content validity of the tool, as follows. Also 10 of Health Education experts were interviewed to obtain their professional opinion about the questionnaire. After the experts assessment and consultation with members of the research team were applied necessary change. In addition, the designed tool was then emailed to a 10 of Health Education experts. Their views about questionnaire items were assessed based on a three-point Likert scale consisting of Necessary, helpful but not necessary, and not necessary (CVI) and four-point Likert consisting of "relevance", "clarity", and "simplicity". Then the content validity ratio (CVR) and the content validity index (CVI) were determined. According to the Lawsche table content validity ratio for 70 items was calculated above 0.62 . Questionnaire items had a score of content validity index over than 0.7 . Reliability of the questionnaire was assessed through test-retest method. To calculate the reliability coefficient, 20 IDA members (type 2 diabetes patients) completed the questionnaire twice at a two week interval in a pilot study. Cronbach's alpha was calculated for each of the seven domains as follows: $0.82,0.89,0.92,0.90,0.87,0.91$ and 0.92 . The individuals who participated in the pilot study were excluded from the main study. A five-point Likert scale was used for the answers, ranging from 'strongly agree' to 'strongly disagree'. The questionnaire included the following sections; the demographic section (5 questions), knowledge (14 questions), perceived susceptibility (5 questions), perceived threat (3 questions), perceived benefits ( 7 questions), perceived barriers (11 questions) and cues to action (10 questions). The self-efficacy dimension included 20 questions with Likert-type answers, ranging from 5 to 1 . Overall, the questionnaire contained 70 questions. The lowest possible score obtained in the questionnaire was 20 , and the highest was 100 .

The educational program was designed based on HBM component for promotion of health behaviors among patient with diabetes. This program was included educational classes and educational booklets. The content of the booklet was included definitions of diabetes, symptoms, risk factors and the benefits of adopting healthy behaviors to prevent long-term complications of diabetes, introduce needed resources to get more information such as Reputable websites Diabetes Control Centers and Clinics. Six months after the intervention, data were again collected through the questionnaire in both groups. Trained health professionals were completed questionnaires by face to face interview during one hour for each person. A free visit to the doctor was given to all successful patients (those whose self-efficacy had improved over the educational course) at the end of the study. Ethical approval for this study was obtained from the Research Ethic Committee of Iran University of Medical Sciences. All the patients had signed the informed consent. The participants were free to continue or give up the procedures at any time during the study. They were assured of the confidentiality of their information.

\subsection{Statistical Analysis}

Finally, data were analyzed using SPSS 18. Data analysis was done by Chi-square Test, Pearson's correlation, Independent samples T-test and paired T-test. The Significance level was considered as 0.05 .

\section{Results}

A total of 80 patients with type 2 diabetes were involved in this study. Among the 80 patients, the mean age in the intervention and control groups was $54.87 \pm 9.32$ and $55.45 \pm 8.55$ year's respectively. 72.5 percent of patients (58 participants) were married and a large proportion had low income and used diabetes pills. The popula- 
tion under study was mainly unemployed and had elementary \& secondary school education. The results of the study showed that there was no significant difference between the two groups in terms of: gender, marital status, and economic status, mode of treatment, health insurance, educational status, employment status, and presence of people with type 2 diabetes in the family (Table 1).

Table 1. Distribution of demographic variables between the two groups before the educational intervention.

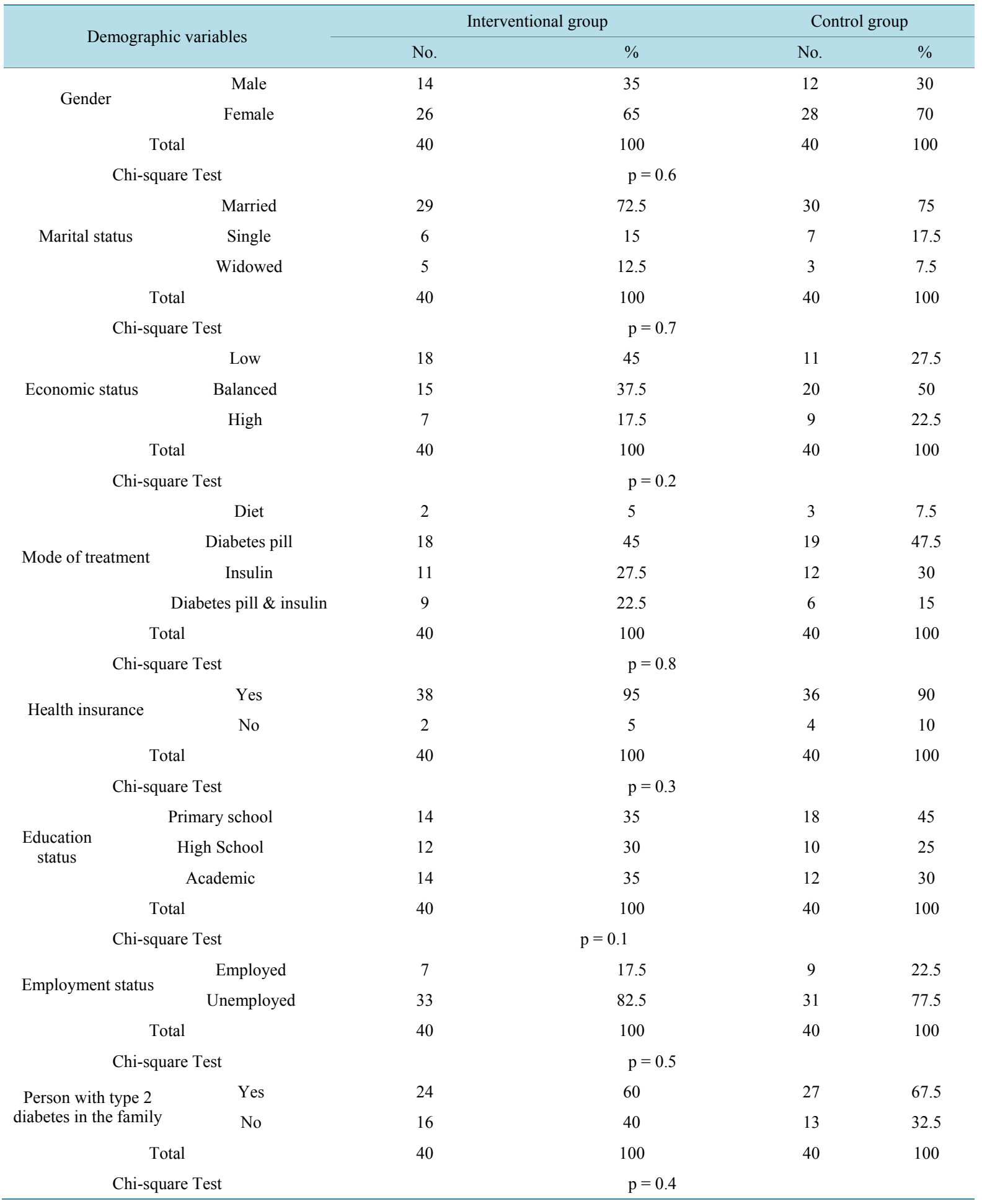


Before intervention, no significant difference was detected between the two groups. However, after the intervention all variables were significantly different except for 'perceived threat' $(p=0.1)$ (Table 2). Results showed that there were significant linear relationships between self-efficacy and all HBM components after the educational intervention in both groups $(\mathrm{p}<0.05)$ (Table 3$)$.

\section{Discussion}

Studies conducted on type 2 diabetes patients have yielded different results, depending on the type of education provided. The Health belief model provides a means to understand the attitude, behaviors and educational needs of people and can therefore be used as a practical tool to develop effective intervention strategies [17].

The paired T-test showed that there was no significant difference in self-efficacy between the two groups before the intervention. This means that the patients' recognition of self-efficacy is about average. Because the mean age in the two groups was over 45 years, they were more likely to have complications from diabetes and other illnesses. So their performance in self-care activities was not high, and generally speaking, more efforts were needed to enhance self-efficacy in diabetes management [18] [19]. In our study, self-efficacy was significantly higher in the intervention group after the intervention. These changes may have occurred as a result of patient participation in the educational course. This finding was similar to the findings of other studies (Morowati sharifabad et al. (2009) [20].

Table 2. Comparison of Health belief model components before and after the educational intervention.

\begin{tabular}{|c|c|c|c|c|c|}
\hline \multirow{2}{*}{ Variables } & \multirow{2}{*}{ Group } & \multicolumn{2}{|c|}{ Before intervention } & \multicolumn{2}{|c|}{ After intervention } \\
\hline & & Mean & SD & Mean & SD \\
\hline \multirow{2}{*}{ Self-efficacy } & Intervention & 40 & 16.94 & 59.50 & 17.23 \\
\hline & Control & 41.27 & 15.59 & 44.9 & 12.19 \\
\hline Paired T-test & \multicolumn{3}{|c|}{$\mathrm{p}=0.7$} & \multicolumn{2}{|c|}{$\mathrm{p}<0.001$} \\
\hline \multirow{2}{*}{ Knowledge } & Intervention & 9 & 2.54 & 12 & 1.69 \\
\hline & Control & 9.8 & 2.35 & 10.67 & 2.23 \\
\hline Independent T-test & \multicolumn{3}{|c|}{$\mathrm{p}=0.1$} & \multicolumn{2}{|c|}{$\mathrm{p}=0.004$} \\
\hline \multirow{2}{*}{$\begin{array}{c}\text { Perceived } \\
\text { susceptibility }\end{array}$} & Intervention & 6.65 & 3.82 & 11.52 & 3.88 \\
\hline & Control & 7.25 & 3.95 & 8.1 & 3.7 \\
\hline Independent T-test & \multicolumn{3}{|c|}{$\mathrm{p}=0.4$} & \multicolumn{2}{|c|}{$\mathrm{p}=0.001$} \\
\hline \multirow{2}{*}{$\begin{array}{c}\text { Perceived } \\
\text { threat }\end{array}$} & Intervention & 7.05 & 3.87 & 8.92 & 2.58 \\
\hline & Control & 7.45 & 3.61 & 8.07 & 3.09 \\
\hline Independent T-test & \multicolumn{3}{|c|}{$\mathrm{p}=0.6$} & \multicolumn{2}{|c|}{$\mathrm{p}=0.1$} \\
\hline \multirow{2}{*}{$\begin{array}{c}\text { Perceived } \\
\text { barriers }\end{array}$} & Intervention & 22 & 9.32 & 32.72 & 9.48 \\
\hline & Control & 23.52 & 7.85 & 24.8 & 6.5 \\
\hline Independent T-test & \multicolumn{3}{|c|}{$\mathrm{p}=0.4$} & \multicolumn{2}{|c|}{$\mathrm{p}=0.001$} \\
\hline \multirow{2}{*}{$\begin{array}{c}\text { Perceived } \\
\text { benefits }\end{array}$} & Intervention & 14 & 5.93 & 20.82 & 6.03 \\
\hline & Control & 15.02 & 5.21 & 15.8 & 4.4 \\
\hline Independent T-test & \multicolumn{3}{|c|}{$\mathrm{p}=0.4$} & \multicolumn{2}{|c|}{$\mathrm{p}=0.001$} \\
\hline \multirow{2}{*}{ Cues to action } & Intervention & 12.3 & 1.5 & 14.12 & 1.8 \\
\hline & Control & 12.22 & 1.18 & 12.37 & 1.19 \\
\hline Independent $\mathrm{T}$-test & \multicolumn{3}{|c|}{$\mathrm{p}=0.8$} & \multicolumn{2}{|c|}{$p=0.001$} \\
\hline
\end{tabular}


Table 3. Correlation between health belief model components and self-efficacy after the educational intervention.

\begin{tabular}{cccc}
\hline \multirow{2}{*}{ Health belief model components } & Group & \multicolumn{2}{c}{ Self-efficacy } \\
\cline { 3 - 4 } Knowledge & & $\mathrm{p}$-value & Pearson's correlation (r) \\
& Intervention & $\mathrm{p}<0.001$ & 0.7 \\
Perceived susceptibility & Control & 0.03 & 0.56 \\
& Intervention & $\mathrm{p}<0.001$ & 0.85 \\
Perceived threat & Control & 0.02 & 0.6 \\
& Intervention & $\mathrm{p}<0.001$ & 0.72 \\
Perceived benefits & Control & 0.04 & 0.58 \\
& Intervention & $\mathrm{p}<0.001$ & 0.92 \\
Perceived barriers & Control & $\mathrm{p}<0.001$ & 0.83 \\
& Intervention & $\mathrm{p}<0.001$ & 0.95 \\
Cues to action & Control & 0.01 & 0.66 \\
& Intervention & 0.03 & 0.84 \\
\hline
\end{tabular}

The present study showed that before the intervention the participants' mean knowledge score was low, but after the intervention there was a significant difference between the two groups' knowledge and self-efficacy scores (Table 2). Pearson's correlation also showed a significant difference between the two groups' self-efficacy and knowledge scores (Table 3). This finding implies that increased self-efficacy may be due to the intervention group's increased level of knowledge $(r=0.7, p<0.001)$. This increase may therefore be attributed to the educational program. These results are consistent with results of two other studies [21] [22]. This finding is in contrast with Mazloomy et al.'s study (2010). In Mazloomy's study, there was no significant correlation difference between knowledge and self-efficacy [23]. According to their study, increased knowledge of disease risk does not necessarily lead to improvement of self-efficacy in diabetes. But in this study, when the mean score of knowledge increases, self-efficacy of patients increases.

There was no significant difference between the mean scores of perceived susceptibility in the intervention and control groups before intervention either (Table 2). These results are similar to Zandi et al.'s (2007) findings [24]. However, after the intervention there was a significant difference between the two groups' self-efficacy and perceived susceptibility scores. This means that the increased perceived susceptibility following intervention leads to increased self-efficacy in the intervention group $(\mathrm{r}=0.85, \mathrm{p}=0.001)$ (Table 3). These results are consistent with Mazloomy et al.'s study (2010) and findings of a study in Kermanshah which reveal that increased perceived susceptibility in patients helps prevent and control their diabetic foot complications [24] [25]. According to another study conducted in Iran, low perceived susceptibility is one reason why patients do not care about their health. Our results showed that the participants' mean perceived threat score was low in the intervention and control groups before the intervention. The results are similar to Vickie et al.'s results, indicating that the perceived threat of amputation was low among patients with type 2 diabetes before intervention [10] [24]. However, according to our findings, there was no significant difference between the two groups' mean perceived threat scores after the intervention, meaning that the educational program did not affect it (Table 2). These findings are consistent with Aljasem et al. (2001) and others' studies [25] [26]. However, Pearson's r showed significant differences between perceived threat and self-efficacy in the two groups after intervention (Table 3). This means that increased perceived threat leads to increased self-efficacy in the intervention group after training $(r=0.72, p<0.001)$ (Table 3). Self-efficacy and perceived threat may therefore influence the prediction of patient behavior. Therefore, the health belief model can predict and change behavior in patients with diabetes [6]. The study adds to the literature by demonstrating that strategies undertaken to reduce the risk will positively influence knowledge and attitudes and hopefully lead to changes in health behaviors. Highlighting the threat of diabetes and its associated cardiovascular risks may provide a theoretical basis for encouraging patients toward reducing their health risks [27] [28]. The effect of education on self-efficacy is apparent, so education can expose the potential ability of capable individuals in taking concrete measures toward self-care [6]. Our results also indicated a reduction in perceived barriers following the intervention in both groups, which was however more prominent in the intervention group. Polly (1997) showed a significant relationship between per- 
ceived severity and barriers with blood sugar control [29]. These results have been repeated in Shamsi et al.'s (2010) study [30]. The contrast between Zandi's study and ours could be due to the difference in the type of study, where no significant difference was found between the two groups after intervention [4] [24]. In our study, Pearson's $r$ showed significant differences between self-efficacy and perceived barriers in the two groups after intervention (Table 3). Mazloomi et al. (2010) also showed a significant correlation between preventive behaviors and perceived barriers, a finding similar to ours [23].

The results showed that patients' perceived benefits of diabetes care were at a low level in both groups before the educational intervention. Following the intervention, the perceived benefits had increased by 20.85 scores in the intervention group, which was 7 times more than in the control group (Table 2). The results were similar to the findings of other studies by Koch (2002), Sharifirad (2007), Aghamolaie (2005), and Shamsi et al. (2010); and were contradictory to Zandi et al.'s findings (2007) [1]-[6]. Pearson's test demonstrated significant changes in this part as well $(r=0.2, p=0.001)$ (Table 3). The patients who had been exposed to the relevant knowledge acknowledged the benefits of the behavior [6].

Furthermore, there is an internal cue to action that encourages patients to care for themselves. As an external cue to action, the contribution of family members in caring for the disease is also very important [23]. The results of this study showed that participants' cues to action were low in both groups before the intervention (Table $2, p=0.8$ ). However, after the intervention, there were significantly higher differences between the mean "cues to action" scores of the two groups (Table 2). This shows the effectiveness of the educational program. Pearson's test demonstrated significant differences between self-efficacy and cues to action after the intervention $(\mathrm{r}=0.84, \mathrm{p}=0.03)$ (Table 3). This finding was in contrast with Borhani et al.'s study (2010) [7], where promoting patients' general knowledge did not differ between mass media and education delivered by physicians. Furthermore, books, magazines and educational pamphlets had little effect on guiding patients with type 2 diabetes toward health beliefs. The limitations of this study can be mentioned that participants want to subscribe to the Iranian Diabetes Society as a Non-Government Organization (NGO), so they are different from other patients in terms of socioeconomic status. Therefore, it seems this result is generalizable to this group of patients.

All the health belief model components changed after the educational intervention in this study, especially self-efficacy. Generally, the results of this study indicate that the health belief model is a suitable model that can help change patient behavior. Therefore, it may be applied in programs promoting self-management behavior among patients with type 2 diabetes. There are several limitations in the present study. In this study patients follow up a short period of time after the education. Therefore, a long term follow-up will be recommended. This study should be done on a larger sample size. Also participants of the study were members of Diabetes Association as Non-Government Organization. These people may differ in terms of social and economic characteristics. This study should be done in the future among the total population.

\section{Acknowledgements}

The project was supported by a grant from the Vice-Chancellor of Research \& Technology of Iran University of Medical Sciences (grant Number: 3182806). This research is registered in The Iranian Registry of Clinical Trials (clinical registration number: 138811191693N4). We also thank maleki $\mathrm{k}$ Dr. This research paper is made possible through the help and support from everyone, including patients and the Iranian Diabetes Association.

\section{References}

[1] Khoshniat Niko, M., Madarshahian, F., Hassanabadi, M., Heshmat, R. and Khaleghian, N. (2007) Comparative Study of Cognitive Status in Elderly with and without Type 2 Diabetes. Iranian Journal of Diabetes and Metabolism, 7, 7176.

[2] Ramachandran, A., Snehalatha, C., Mary, S., Mukesh, B., Bhaskar, A. and Vijay, V. (2006) The Indian Diabetes Prevention Programme Shows That Lifestyle Modification and Metformin Prevent Type 2 Diabetes in Asian Indian Subjects with Impaired Glucose Tolerance (IDPP-1). Diabetologia, 49, 289-297. http://dx.doi.org/10.1007/s00125-005-0097-z

[3] Esteghamati, A., Gouya, M.M., Abbasi, M., Delavari, A., Alikhani, S., Alaedini, F., et al. (2008) prevalence of Diabetes and Impaired Fasting Glucose in the Adult Population of Iran National Survey of Risk Factors for Non-Communicable Diseases of Iran. Diabetes Care, 31, 96-98. http://dx.doi.org/10.2337/dc07-0959

[4] Rosenstock, I.M., Strecher, V.J. and Becker, M.H. (1988) Social Learning Theory and the Health Belief Model. Health 
Education \& Behavior, 15, 175-183. http://dx.doi.org/10.1177/109019818801500203

[5] Rosenstock, L. (1974) Historical Origins of The Health Belief Model.

[6] Safari, M. and Shojaeizadeh, D. (2009) Theories Models and Methods of Health Education and Promotion. Asar-E Sobhan Publishing, Iran, 22-24.

[7] Borhani, F., Abbaszadeh, A., Taebi, M. and Kohan, S. (2010) The Relationship between Self-Efficacy and Health Beliefs among Type 2 Diabetic Patients.

[8] Harvey, J. and Lawson, V. (2009) The Importance of Health Belief Models in Determining Self-Care Behaviour in Diabetes. Diabetic Medicine, 26, 5-13. http://dx.doi.org/10.1111/j.1464-5491.2008.02628.x

[9] Aghamolaei, T., Eftekhar, H., Mohammad, K., Sobhani, A., Shojaeizadeh, D., Nakhjavani, M., et al. (2005) Influence of Educational Intervention Using Interaction Approach on Behavior Change, Hemoglobin Alc and Health-Related Quality of Life in Diabetic Patients. Journal of School of Public Health and Institute of Public Health Research, 3, 1-2.

[10] Hazavehei, S., Sharifirad, G. and Mohabi, S. (2007) The Effect of Educational Program Based on Health Belief Model on Diabetic Foot Care. International Journal of Diabetes in Developing Countries, 27, 82-90.

[11] Krichbaum, K., Aarestad, V. and Buethe, M. (2003) Exploring the Connection between Self-Efficacy and Effective Diabetes Self-Management. The Diabetes Educator, 29, 653-662. http://dx.doi.org/10.1177/014572170302900411

[12] Whitley, E. and Ball, J. (2002) Statistics Review 4: Sample Size Calculations. Critical Care, 6, 335-341. http://dx.doi.org/10.1186/cc1521

[13] Israel, G.D. (1992) Determining Sample Size: University of Florida Cooperative Extension Service, Institute of Food and Agriculture Sciences, EDIS.

[14] Given, C.W., Given, B.A., Gallin, R.S. and Condon, J.W. (1983) Development of Scales to Measure Beliefs of Diabetic Patients. Research in Nursing \& Health, 6, 127-141. http://dx.doi.org/10.1002/nur.4770060306

[15] Gillibrand, R. and Stevenson, J. (2006) The Extended Health Belief Model Applied to the Experience of Diabetes in Young People. British Journal of Health Psychology, 11, 155-169. http://dx.doi.org/10.1348/135910705X39485

[16] Zareban, I., Niknami, S., Hidarnia, A., Rakhshani, F., Shahrakipour, M. and Moshki, M. (2013) The Effect of Education Based on Health Belief Model on Reduction of HbA1c Level in Diabetes Type 2. Journal of Research \& Health, 3, 370-378.

[17] Kloeblen, A.S. and Batish, S.S. (1999) Understanding the Intention to Permanently Follow a High Folate Diet among a Sample of Low-Income Pregnant Women According to the Health Belief Model. Health Education Research, 14, 327-338. http://dx.doi.org/10.1093/her/14.3.327

[18] Vosoghi Karkazloo, N., Abootalebi Daryasari, G., Farahani, B., Mohammadnezhad, E. and Sajjadi, A. (2012) The Study of Self-Care Agency in Patients with Diabetes (Ardabil). Modern Care Journal, 8, 197-204.

[19] Charron-Prochownik, D., Sereika, S.M., Becker, D., Jacober, S., Mansfield, J., White, N.H., et al. (2001) Reproductive Health Beliefs and Behaviors in Teens with Diabetes: Application of the Expanded Health Belief Model. Pediatric Diabetes, 2, 30-39. http://dx.doi.org/10.1046/j.1399-543x.2001.00000.x-i5

[20] Morowatisharifabad, M. and Tonekaboni, N.R. (2009) Perceived Self-Efficacy in Self-Care Behaviors among Diabetic Patients Referring to Yazd Diabetes Research Center. Journal of Birjand University of Medical Sciences, 15, 91-99.

[21] Moghadamtabrizi, F., Mohadesi, H. and Babayee, H. (Eds.) (2002) The Survey of Need Educational Diabetes about Selfcare Referring to Taleghani Hospital Urmia. Abstract Second Public Health Congress, Kermanshah University of Medical Science.

[22] Baghyani-Moghadam, M., Shafiei, F., Haydarneia, A. and Afkhami, M. (2005) Efficacy of BASNEF Model in Controlling of Diabetic Patients in the City of Yazd, Iran. Indian Journal of Community Medicine, 30, 10-12.

[23] Mazloomy, S., Mirzaei, A., Afkhami Ardakani, M., Baghiani Moghadam, M. and Fallahzadeh, H. (2010) The Role of Health Beliefs in Preventive Behaviors of Individuals at High-Risk of Type 2 Diabetes Mellitus. The Journal of Shahid Sadoughi University of Medical Sciences, 18, 24-31.

[24] Asadzandi, M., Farsi, Z., Najafi Mehri, S. and Karimizarchi, A.A. (2006) Educational Intervention Focusing on Health Belief Model in Health Beliefs, Awareness and Behavior of Diabetic Patients. Iranian Journal of Diabetes and Lipid Disorders, 6, 169-176.

[25] Gh, S., Hazavehi, M., Baghianimoghadam, M. and Mohebi, S. (2007) The Effect of a Health Belief Model based education program for foot care in diabetic patients type II in Kermanshah, Iran (2005). International Journal of Endocrinology and Metabolism, 5, 82-90.

[26] Aljasem, L.I., Peyrot, M., Wissow, L. and Rubin, R.R. (2001) The Impact of Barriers and Self-Efficacy on Self-Care Behaviors in Type 2 Diabetes. The Diabetes Educator, 27, 393-404. http://dx.doi.org/10.1177/014572170102700309

[27] Ayele, K., Tesfa, B., Abebe, L., Tilahun, T. and Girma, E. (2012) Self Care Behavior among Patients with Diabetes in 
Harari, Eastern Ethiopia: The Health Belief Model Perspective. PLoS ONE, 7, e35515. http://dx.doi.org/10.1371/journal.pone.0035515

[28] Whitford, D.L., McGee, H. and O'Sullivan, B. (2009) Reducing Health Risk in Family Members of Patients with Type 2 Diabetes: Views of First Degree Relatives. BMC Public Health, 9, 455. http://dx.doi.org/10.1186/1471-2458-9-455

[29] Polly, R.K. (1992) Diabetes Health Beliefs, Self-Care Behaviors, and Glycemic Control among Older Adults with Non-Insulin-Dependent Diabetes Mellitus. The Diabetes Educator, 18, 321-327. http://dx.doi.org/10.1177/014572179201800411

[30] Shamsi, M., Sharifirad, G., Kachoyee, A. and Hassanzadeh, A. (2009)The Effect of Educational Program Walking Based on Health Belief Model on Control Sugar in Woman by Type 2 Diabetics. Iranian Journal of Endocrinology and Metabolism, 11, 490-499, 597. 